300

Content list available at: https://openpsychologyjournal.com

RESEARCH ARTICLE

\title{
Perceived Stress of Special Education Teachers in the Context of the Person- Environment Relationship
}

\author{
Olufemi T. Adigun ${ }^{1, *}$, Faizat A. Tijani ${ }^{2}$, Dumisani R. Nzima ${ }^{1}$ and Raveenthiran Vivekanantharasa ${ }^{3}$ \\ ${ }^{I}$ Department of Educational Psychology and Special Education, University of Zululand, KwaDlangezwa, South Africa \\ ${ }^{2}$ Oakwood Montessori School, Surulere, Lagos, Nigeria \\ ${ }^{3}$ Department of Secondary and Tertiary Education, Faculty of Education, The Open University of Sri Lanka, Colombo, Sri Lanka
}

\begin{abstract}
:
Background:

The teachers of learners with special needs are confronted with higher demands, enormous challenges and low reward or motivation. Hence, stress among the teachers is inevitable with a resultant effect on behavioural and learning outcomes of learners with special needs. Unfortunately, factors that contribute to perceived stress among teachers of learners with special needs, particularly in Southwest Nigeria, are yet to be established.

Objective:

To establish the relationship of some personal and environment-related factors as determinants of stress among teachers of learners with specia needs.

\section{Methods:}

A total of 118 participants were randomly selected from special schools in South west Nigeria. A descriptive survey of both a quantitative and qualitative research design was adopted. Based on the person-environment fit theory, four research questions were raised and answered. A structured questionnaire and semi-structured interview were used for data collection. Quantitative data were analysed with descriptive statistics and inferential statistics at a 0.05 level of significance, while qualitative data were thematically analysed.

Results:

The study found a significant positive relationship between the student-teacher relationship and perceived stress and an inverse relationship of work experience and work motivation with perceived stress among the participants. An unfavourable working environment and lack of motivation were identified by the participants as major sources of stress.

Conclusion:

The study concluded that work environment-related factors triggered stress among teachers of learners with special needs.
\end{abstract}

Keywords: Perceived stress, Teachers of learners with special needs, Work motivation, Student-teacher relationship, Work experience, Educational attainment.

\section{Article History}

$$
\text { Received: April 20, } 2021
$$

Revised: June 14, 2021

Accepted: June 29, 2021

\section{INTRODUCTION}

Learners with special needs represent a heterogeneous group of individuals with diverse needs. They are those who may be living with physical, cognitive or sensory disabilities, which may either be congenital or acquired. In addition, they

\footnotetext{
* Address correspondence to this author at the Department of Educational Psychology and Special Education, University of Zululand, KwaDlangezwa, South Africa; Tel: 0788396897; E-mail: olufemiadigun@yahoo.com
}

have peculiarities of moderate to profound effects of their disabilities on their social, behavioural and educational activities. Perceptions and attitudes of people in developing countries like Nigeria have exacerbated marginalisation experiences and redshirting of school activities among children living with disabilities $[1,2]$. Among the approximately 10.5 million school-age children in Nigeria, many are living with disabilities [3]. Children with disabilities are enrolled in either government-owned or privately owned inclusive, 
mainstreamed or segregated special schools across the country [4 - 6]. In Nigeria, like in many other developing nations in sub-Saharan Africa, concerns about the education of children with disabilities via more appropriate strategies are on the increase. Hence, there is a shift in the ideology, policies, philosophies, and frameworks on how to better place children with disabilities in teaching and learning situations that best suit their physical, social, cognitive, behavioural and educational needs.

Essentially teachers, irrespective of their school type (privately or publicly owned schools), are at the centre of educational provision to learners with special needs. They extensively strive to implement the curricula using appropriate teaching strategies that respond to the behavioural, cognitive and learning abilities of each learner irrespective of their disabilities. In addition to ensuring adherence to implementation of the curricula and knowledge impartation and enhancement of the learning outcomes of learners with special needs, teachers of these learners often contend with excessive behavioural characteristics, such as hyperactivity, impulsivity, self-injury, anxiety and/or aggressiveness of learners and other psycho-physiological features that may prevent effective teaching and learning processes. Hence, it may be said that the teachers of learners with special needs have an enormous job and a difficult task when teaching these learners with diverse educational needs. According to Cancio et al. [7], Kokkinos and Davazoglou [8] and Kuvaeva [9], working with learners with special needs is highly stressful work. Stress is thus inevitable among teachers of learners with special needs $[9,10]$, especially when the teaching workload is not well managed and teachers are not well motivated.

Although not all stress experienced by teachers of learners with special needs is deleterious [11], unmanaged stress among these teachers in special schools may lead to deleterious effects on job performance, attrition and absenteeism. Studies have established that teachers in special schools are confronted with higher demands, enormous challenges and low reward or motivation that may prevent them from giving their best to the educational and behavioural enhancement of learners with special needs $[8,11,12]$. The literature on stress among teachers indicates that teachers in special schools exhibit higher levels of stress than teachers in ordinary needs schools $[8,10$, 12, 13]. However, Ghani et al. [11] have recorded only a moderate level of stress among some Malaysian special needs education teachers in comparison to their counterparts teaching in schools for non-disabled learners. Moderate to high-stress levels experienced by teachers of learners with special needs are due, in part, to additional resources, attention and modification of the curriculum given by teachers to learners with special needs. Other factors are an unfavourable working environment, poor conditions of service and inequitable rewards for teaching services rendered to learners with special needs despite the educational qualifications of the teachers [12].

In Nigeria, a few studies with digital visibility [10, 14] have examined the levels of perceived stress among teachers teaching in special educational settings. Such studies have established that stress among this set of Nigerian teachers is high. However, the determinants of the magnitude of the perceived stress are yet to be established. Some studies [7, 8, 12] assert that teaching learners with special needs is a challenging task, which requires exceptional skills and dexterity in classroom management and lesson preparation, resource management and pedagogical applications, as well as assessment and evaluation of learning outcomes. Special educational needs teachers have an increased workload with the use of Individualised Educational Programmes (IEP) crafted by teachers to meet learners' specific needs, especially in inclusive educational programmes. Irrespective of any type of educational provisions (inclusive, mainstream or segregated) for learners with special needs, with the use of IEP, teachers exert more effort, time and energy to craft, design, implement and review IEPs for each learner based on his/her academic and behavioural potential. Despite no or very minimal opportunities for education and training scholarships from the Nigerian government or institutional support, many teachers of learners with special needs in Nigeria have acquired the requisite educational qualifications and skills, as stipulated by the establishment Act (TRCN Act CAP T3 of 2004) of the Teachers Registration Council of Nigeria [15].

However, despite personal education attainment and teaching qualifications obtained, teachers of learners with special needs remain one of the less remunerated groups of professionals in Nigeria [16]. Teachers of learners with special needs with the requisite educational qualification but earning meagre salaries may express various levels of stress. Documented reports of the implications of educational qualifications and perceived stress among teachers of learners with special needs are scanty. However, the literature on teachers in regular schools reveals divergent results. Okeke and Dlamini [17] assert that educational qualification or attainment and teachers' stress has no relationship. In other words, irrespective of the level of educational certificates obtained, the stress experienced by teachers remains the same. Conversely, Aftab and Khatoon [18] posit that stress among teachers is a function of their qualifications. They argue that, with higher educational qualifications and less pay, the tendency of perceived stress is likely to be higher among teachers. Also, a very recent study among school teachers in Gondar, Ethiopia, reveals that teachers with lower educational qualifications are $66 \%$ likely to be more stressed [19]. However, Darmody and Smyth [20] report no significant differences in educational level and work stress among teachers.

With requisite educational qualifications and employment opportunities in special schools, teachers garner experience on the job and sharpen their classroom management skills, and this may reduce their perceived stress. According to Berger et al. [21], years of work experience as a teacher is an essential factor in how teachers handle issues within the classroom, among peers and/or with school administrators. Following a comparison of novice teachers and those with about ten years of teaching experience, Berger et al. [21] suggest that based on years of teaching, teachers have great potential to better anticipate issues and adapt and cultivate a superior ability to understand learners' behaviour and classroom management practices accordingly. Although how years of teaching experience influence the perceived stress among teachers of 
learners with a disability is understudied, especially in Nigeria and many other sub-Saharan African countries. It was found that the ability to resolve organisational conflicts, which may spur stress among teachers is better developed by teachers with a reasonable number of years of teaching experience [22]. This assertion lends credence to Kabito and Wami's [19] finding of more work-related stress among some Ethiopian teachers with less than five years of teaching experience as compared to those with $\geq$ sixteen years of teaching experience. Also, Shkëmbi et al. [23] have found a relationship between years of teaching experience and work-related stress in Kosovo. However, some studies have found no relationship between years of teaching experience and perceived stress levels [24, 25].

During the years of teaching, one major construct that cannot be separated from teaching and learning processes is the relationship between the teachers and their learners. Breaks in the chain of cordial relationships between teachers and learners may negatively affect learning and behavioural outcomes; hence the relationship between learners/students and their teachers/instructors, particularly for learners with special needs, is paramount. Previous studies have presented the effects of the teacher-student relationship on the behavioural dimension and learning outcomes of learners with special needs [26 - 29]. Many of the previous studies have also indicated that the extent of the student-teacher relationship reflects the level of acceptance or rejection of such learners among their peers and society [28, 30 - 33]. However, some studies [34, 35] conducted in developed countries have examined the implications of the teacher-student relationships on the perceived stress among the teachers of learners with special needs.

As indicated by Brunsting et al. [34] and Kiel et al. [35], teachers of learners with special needs might be susceptible to emotional exhaustion, frustration and higher levels of stress in their bid to ensure enhanced behavioural and learning outcomes among learners with special needs. The severity and type of disabilities presented in the classroom may heighten teachers' levels of frustration, emotional exhaustion and stress [36, 37]. As found by Shevlin et al. [37], teaching learners in an inclusive setting exacerbates the stress experienced by teachers. This is, perhaps, because teachers have several academic and behavioural characteristics to manage at the same time. Owing to the peculiarities associated with each learner with special needs, it is expected that the teacherstudent ratio should be minimal. The classroom situations in Nigerian public primary schools are appalling, with a lack or inadequacy of basic facilities, and most times, the classrooms are overcrowded [38, 39]. Teachers in such situations may be prone to job stress; thus an examination of the impact of teacher-learner relationships vis-à-vis the perceived stress of the teachers of learners with special needs, especially in a developing nation like Nigeria, is essential.

While studies $[10,12,14]$ have established that stress among teachers in special schools is heightened, other studies have indicated that motivation to work vis-à-vis its sources is paramount for teachers' job satisfaction and stress relief [40, 41]. Motivation (delineated as intrinsic and extrinsic) refers to vibrant processes with greater potential to affect communication, productivity, cooperation, the emotional and physical state, career fulfilment and self-fulfilment, and the working atmosphere. Both intrinsic motivation and extrinsic motivation are essential for stress-free jobs and job satisfaction for teachers. Dombrovskis et al. [40] provide evidence that a positive work climate, competitiveness among teachers, appropriate remuneration, as well as personal and professional growth are sources of motivation evident in teachers' morale and how well they are satisfied with their jobs. Yasmeen et al. [42], in their study among special education teachers in Punjab, Pakistan, have revealed that teachers of learners with special needs are intrinsically motivated to execute their duties as teachers; however, the state of extrinsic motivators among the teachers is grossly inadequate.

Special education teachers are ill-treated and paid salaries, which are incommensurable with their input made in teaching learners with special needs. Yasmeen et al. [42] note that limited chances of securing promotion as and when due, dilapidated or even unavailable teaching facilities and a lack of special teacher allowances remain part of the regular experiences of teachers in special schools. However, many of the previous studies have failed to assess work motivation among the teachers of learners with special needs in relation to the perceived stress of these teachers. Many studies have explored various school environments and teachers' motivation with respect to job performance and students' learning outcomes [43 - 47]. Therefore, in order to advance research knowledge on the relationship between work motivation and perceived stress, particularly among teachers in special schools, we hypothesise that work motivation may predict perceived stress among teachers of learners with special needs.

\section{THEORETICAL FRAMEWORK}

This study is anchored to the person-environment (P-E) fit theory [48]. This theory is based on the assumption that there is a deep sense of connection between a person and his/her environment. The P-E fit theory, according to $\mathrm{Yu}$ [49], emphasises the interactions between what makes up a person and his/her environment. In other words, an individual seeks and strives to fit in an environment that matches his/her characteristics in a manner that is consistent with a reduced level of uncertainty and a moderate to a high level of happiness and satisfaction. This implies that an existing fit between a person and his/her environment may have implications for his/her psychosocial well-being. A misfit of P-E may result in the expression of maladaptive behaviours, deterioration in physical and mental well-being, as well as stressful experiences, especially in the workplace, which eventually results in increased morbidity and mortality. Within the teaching space, a teacher's physical, social and emotional reactions to events may largely be motivated by personal characteristics or factors within the school environment. As expressed by Okeke and Dlamini [17], teachers are often trapped between personal and professional conflicts but may strive to adjust to situations for the sake of the learners. Thus, it may be assumed that there is a greater tendency for disequilibrium, strife, dissatisfaction and heightened stress among teachers of learners with special needs and 
inharmonious teacher-student relationships when a negative PE fit exists within the school environment. There is a dearth of studies on the influence of personal (gender, educational attainment, work experience) and environment-related (student-teacher relationships and work motivation) factors that exist among teachers of learners with special needs in Nigeria. Therefore, this study, using the P-E fit theory as the theoretical lens, answers the following questions:

- Is there a significant relationship between gender, educational attainment, work experience, studentteacher relationships, work motivation and perceived stress among teachers of learners with special needs?

- Is there a significant joint relationship between work motivation, student-teacher relationships and perceived stress among teachers of learners with special needs? - Is there any significant relative contribution by work motivation, student-teacher relationships on the perceived stress among teachers of learners with special needs?

- Is there a significant difference in perceived stress among teachers of learners with special needs based on gender and work experience?

- What is/are the major source(s) of perceived stress among the teachers of learners with special needs?

\section{MATERIALS AND METHODS}

\subsection{Study Design}

A mixed-methods research design was adopted for this study. Mixed method research design is an approach by which researchers/investigators collect and analyse both qualitative and quantitative data in a single study, integrate the findings, and draw inferences from both the qualitative and quantitative data [50]. In line with the foregoing, this study engaged mixedmethod approach in order to facilitate and ensure the comparison between the quantitative and qualitative data collected on the personal and environment-related factors and their effect on the perceived stress among teachers of learners with special needs in Southwest Nigeria between June and July 2019.

\subsection{Participants}

One hundred and eighteen teachers of learners with special needs, who were randomly selected from two purposively selected states from South western Nigeria, participated in the study. The participants comprised $44.1 \%$ males and $55.9 \%$ females. About $48.3 \%$ of the participants were aged between 20 and 30 years, $34.7 \%$ were between 31 and 40 years, while $6.4 \%$ and $2.1 \%$ of the study participants were between the ages of 41-50 and $>50$ years, respectively. The majority of the participants $(57.7 \%)$ were Yoruba from western Nigeria, while only $2.5 \%$ of the participants were Hausa from northern Nigeria. The other participants $(39.8 \%)$ were Igbo from the eastern part of Nigeria. All participants were teachers in various special schools within the two selected states in South western Nigeria. Among the 118 teachers, who participated in the study, $63.5 \%$ had the Nigeria Certificate in Education (NCE), 20.4\% held Bachelor's degrees, while $11.9 \%$ and $4.2 \%$ held Master's and Doctoral degrees, respectively.

Furthermore, at the time of data collection, $73.7 \%$ of the participants were teaching learners with special needs in public (government-owned) schools, while the other $26.3 \%$ were teachers of learners with special needs in privately owned schools [50]. Amongst the teachers who participated in the study, $44.9 \%$ were teachers in inclusive schools, $19.5 \%$ taught in segregated schools, and $19.5 \%$ taught in mainstream schools. About $49.2 \%$ of the participants had spent 1 to 5 years $24.6 \%$ had spent 6 to 10 years, $19.5 \%$ had spent 11 to 15 years and $6.8 \%$ had spent $>15$ years as teachers of learners with special needs. In terms of average monthly salaries, $49.2 \%$ of the teachers earned 40,000 - 60,000 Naira monthly (an equivalent of about \$155), 28.7\% earned 61,000 - 80,000 Naira monthly (an equivalent of about \$207), 15.3\% earned 81,000 100,000 Naira monthly (an equivalent of about $\$ 258$ ), while $6.8 \%$, who had spent more than 15 years as teachers, earned more than 100,000 Naira monthly.

\subsection{Measures}

In addition to the demographic information obtained from the participants, other measures employed for data collection in the study are presented below:

\subsubsection{Student-teacher Relationship Scale-short Form}

(STRS-SF): This is a 15-item Student-Teacher Relationship Scale [51] originally designed with a 5-point response format, from $1=$ definitely does not apply, to $5=$ definitely applies. The STRS-SF was adopted for this study. Items in the scale, such as, 'I share an affectionate, warm relationship with this child' were reworded and thus read, 'I share an affectionate, warm relationship with learners with special needs' and the STRS-SF was redesigned in a 4-point Likert response format, from 1 = definitely does not apply to 4 $=$ definitely applies. In other words, the ' $3=$ neutral, not sure' response column in the STRS-SF was expunged to allow for definite responses from the participants. The STRS-SF was revalidated among 20 teachers of learners with special needs, who were not part of the final participants sampled for this study. A Cronbach's alpha value of 0.81 was obtained for the revalidated STRS-SF.

\subsubsection{Work Extrinsic and Intrinsic Motivation Scale (WEIMS)}

The WEIMS designed by Tremblay et al. [52] is an 18item scale that was used in this study to measure motivation among teachers of learners with special needs. It was originally designed in a 7-response format, from $1=$ 'does not correspond at all' to $7=$ 'corresponds exactly.' However, in this study, the 7-response format was changed to a 4-point Likert scale, from $1=$ 'strongly disagree' to $4=$ 'strongly agree.' This scale was revalidated among 20 teachers of learners with special needs who were not part of the teachers eventually sampled in this study. A Cronbach's alpha value of 0.78 was obtained for the revalidated WEIMS.

\subsection{Perceived Stress Scale (PSS)}

The PSS [53] was used to assess the stress experienced by 
teachers of learners with a disability. The PSS is a 10-item scale designed in a 5-response format, from $0=$ 'never' to $4=$ 'very often.' PSS has only four positively-worded items (items 4, 5, $7 \& 8$ ) and six negatively-worded items (items 1, 2, 3, 6, 9 $\& 10$ ). This scale was adapted for this study but was also revalidated among 20 teachers of learners with special needs who were not part of the teachers whose responses were used and analysed in this study. A Cronbach's alpha value of 0.83 was obtained for the revalidated PSS.

In addition to the above, qualitative responses were obtained from eight participants ( 4 males and 4 females) on what constituted stress to them in their duties as teachers of learners with special needs. The interview schedule covered the following key areas: (i) their perception about being a teacher of learners with special needs, (ii) how stressful their job as a teacher of learners with special needs was and (iii) what their major source of perceived stress as a teacher of learners with special needs was.

\subsection{Data Collection Procedure}

In administering the research instrument, permission was sought to conduct the study among teachers of learners with special needs from the school administrators of each school visited in the two states. Permission was granted by the school administrators. In some schools, the principals directed each head of the department to assist in encouraging each teacher to attend to the paper-pencil research instrument, while in others, the school administrators allowed the researchers to approach and solicit teachers' attention to attend to the research instrument.

The researchers, in conjunction with a research assistant, administered copies of the paper-pencil questionnaire to the teachers who participated in this study. This gave the researchers ample time to provide answers to the relevant questions raised by the respondents and to ensure that all the copies of the research instrument were properly filled. One hundred and eighteen copies of the questionnaire, out of the one hundred and fifty copies administered, were either properly filled or returned. In other words, the response rate was $78.7 \%$. This was considered appropriate for a descriptive survey study, according to Bryman [54], who posits that a $60 \%$ response rate is adequate for quantitative survey research. An average of 12 minutes was used to complete the various sections of the research instrument.

Out of the 118 teachers of learners with special needs who responded to the paper-pencil questionnaire, 8 of them (4 males, 4 females) were purposively selected for an in-depth interview in the English language. An interview guide, which was flexible, was used for the interview. The in-depth interview guide was grounded in the issues addressed in the paper-pencil questionnaire. The interview sessions were recorded with voice recorders, and the interpretivist paradigm was adopted.

\subsection{Ethical Consideration}

The participants were duly informed of the objective of the study, and they voluntarily participated in the study. They all gave their informed consent before responding to the research instruments. No compensation was given to any participant. The participants were anonymised and assured of the confidentiality of their responses.

\subsection{Data Analysis}

The quantitative data gathered were analysed with descriptive statistics of frequency counts and simple percentages, as well as inferential statistics involving Pearson Product Moment Correlation and Multiple Regression at alpha $<0.05$ level of significance. Descriptive statistics were used to analyse the demographic information provided by the participants, Pearson Product Moment Correlation was used to analyse the responses related to research question one, Multiple Regression was used to analyse the data for research questions two and three, while the independent-sample T-Test was used to analyse research question four (Table $\mathbf{1}$ ).

Also, in order to answer research question four, the audiorecorded in-depth interviews were transcribed by an independent research assistant. The transcription was then independently checked for accuracy with the notes taken during the interviews. The qualitative data collected via the indepth interviews were thematically analysed. This was done in order to be able to reflect on and provide a deeper understanding of the findings obtained from the quantitative analysis conducted earlier on the factors associated with perceived stress among teachers teaching learners with special needs. The interviews were coded and organised using the repetitive themes identified from the transcribed documents. The iterative process of analysis, comparison, and summarisation of the data collected was carried out. Original supporting responses of the interviewees were presented in quotations.

\section{RESULTS}

\subsection{Research Question One}

Is there a significant relationship between gender, educational attainment, work experience, student-teacher relationships, work motivation and perceived stress among the teachers of learners with special needs?

With regard to this research question, analysis with the Pearson Product Moment Correlation coefficient at a 0.05 level of significance revealed that work experience $(\mathrm{r}=-0.268, p<$ $0.05)$ and work motivation $(\mathrm{r}=-0.685, p<0.05)$ had an inverse relationship with perceived stress among the teachers of learners with special needs. The student-teacher relationship ( $\mathrm{r}$ $=.274, p<0.05)$ had a direct and positive relationship with perceived stress among the teachers who participated in the study. Conversely, gender $(r=0.135, p>0.05)$ and educational attainment $(r=-0.048, p>0.05)$ had no significant relationship with the perceived stress of the participants. This is shown in Table 2. The implication of these findings was that participants with fewer years of work experience with learners with special needs tended to be more stressed on the job. Also, a less motivating work environment could greatly increase and contribute to the perceived stress experienced by the teachers in special schools. In addition, these findings showed that the student-teacher relationship had a direct and positive 
relationship with the teachers' perceived stress. This aspect of the findings indicated that the teachers did not really experience any stress when interacting with their learners, perhaps as they felt that they were doing their jobs and affecting the psychosocial and cognitive development of learners with special needs in a positive manner. The relationships that existed between the teachers and their students could be termed as 'sweet stress.'

\subsection{Research Question Two}

Is there a significant joint relationship between studentteacher relationships, work motivation and perceived stress among teachers of learners with special needs?

In order to provide answers to research question two, Multiple Regression Analysis was conducted to reveal the joint relationships (Table 2) of continuous/independent variables in this study (work motivation and student-teacher relationships) and perceived stress (dependent variable) among the teachers of learners with special needs.

Table 2 reveals the prediction of both work motivation and student-teacher relationships with perceived stress among the study participants. Both independent variables jointly predicted perceived stress among the teachers of learners with special needs. The table also shows a coefficient of multiple correlations (R) of 0.285 and a multiple R square of 0.081 . This means that $8.1 \%$ of the variance in the perceived stress among the participants was accounted for by both predictor variables when taken together. The significance of the composite contribution was tested at $p<0.05$ using the F- ratio at the degree of freedom $(\mathrm{df}=2 / 117)$. The table equally indicates that the Analysis of Variance for the regression yielded an F-ratio of 5.083 (significant at 0.05 level). This implies that all the variables considered in this study jointly contributed to the perceived stress among the teachers of learners with special needs.

\subsection{Research Question Three}

Is there a significant relative contribution by work motivation and student-teacher relationships on the perceived stress among teachers of learners with special needs?

The results captured in Table 3 reveal the relative contribution of the two independent variables to the dependent variable, expressed as beta weights. The standard coefficients of the student-teacher relationship had a positive significant contribution to the perceived stress of the teachers of learners with special needs. Work motivation, however, had an insignificant contribution to the perceived stress of the teachers of learners with special needs. Using the standardised regression coefficient to determine the relative contributions of the independent variables to the explanation of the dependent variable, this study revealed that the student-teacher relationship $(\beta=0.285, \mathrm{t}=3.160, p<0.05)$ was the most potent contributor to the prediction of the perceived stress of the teachers of learners with special needs. These results indicated in Table $\mathbf{3}$ implied that the student-teacher relationship largely influenced the perceived stress of the teachers of learners with special needs.

Table 1. Correlation between all the variables in the study.

\begin{tabular}{|l|l|l|c|c|c|c|c|}
\hline & Variables & $\mathbf{1}$ & $\mathbf{2}$ & $\mathbf{3}$ & $\mathbf{4}$ & $\mathbf{5}$ & $\mathbf{6}$ \\
\hline $\mathbf{1}$ & Perceived stress & 1 & .135 & -.048 & $-.268^{* *}$ & $.274^{* *}$ & $-.685^{*}$ \\
\hline $\mathbf{2}$ & Gender & & 1 & .162 & -.113 & .023 & -.152 \\
\hline $\mathbf{3}$ & Educational attainment & & & 1 & $.255^{* *}$ & -.133 & -.106 \\
\hline $\mathbf{4}$ & Work experience & & & & 1 & -.136 & -.113 \\
\hline $\mathbf{5}$ & Student-teacher relationship & & & & & 1 & .139 \\
\hline $\mathbf{6}$ & Work motivation & & & & & & 1 \\
\hline
\end{tabular}

Table 2. Joint relationships between student-teacher relationship, work motivation and perceived stress.

\begin{tabular}{|c|c|c|c|c|c|}
\hline $\mathbf{R}$ & \multicolumn{2}{|c|}{ R Square } & \multicolumn{2}{c|}{ Adjusted R Square } & \multicolumn{2}{c|}{ Std Error of the Estimate } \\
\hline $0.285^{\mathrm{a}}$ & \multicolumn{2}{|c|}{0.081} & \multicolumn{2}{c|}{0.065} & 5.591 \\
\hline Model & Sum of Squares & Df & Mean Square & $\mathrm{F}$ & Sig. \\
\hline Regression & 317.842 & 2 & 158.921 & 5.083 & $.008^{\mathrm{b}}$ \\
\hline Residual & 3595.751 & 115 & 31.267 & & \\
\hline Total & 3913.593 & 117 & & & \\
\hline
\end{tabular}

a. Dependent Variable: Teacher stress b. Predictors: (Constant), student-teacher, Motivation 
Table 3. Relative contribution of work motivation and student-teacher relationships to the perceived stress among the teachers of learners with special needs.

\begin{tabular}{|c|c|c|c|c|c|}
\hline \multirow{2}{*}{ Model } & \multicolumn{2}{|c|}{ Unstandardized Coefficients } & Standardized Coefficients & \multirow{2}{*}{ Sig. } \\
\cline { 2 - 5 } & B & Std. Error & Beta & & \\
\hline Constant & 11.734 & 5.100 & & 2.301 & 0.023 \\
\hline Work motivation & -0.076 & 0.088 & -0.077 & -0.857 & 0.393 \\
\hline Student-teacher relationship & 0.410 & 0.130 & 0.285 & 3.160 & 0.002 \\
\hline
\end{tabular}

\subsection{Research Question Four}

Is there a significant difference in perceived stress among teachers of learners with special needs based on gender and work experience?

This study further examined the differences between two categorical variables (gender: male and female, work experience: early career and late career) and perceived stress among teachers of learners with special needs. Results obtained, as shown in Table 4 revealed a significant difference in the perceived stress of teachers of learners with special needs $(\mathrm{t}=-1.544 ; \mathrm{p}<0.05)$ based on their years of work experiences while no statistically significant difference was observed in the perceived stress of teachers of learners with special needs $(\mathrm{t}=-1.462 ; \mathrm{p}>0.05)$ based on gender differences.

\subsection{Research Question Five}

What is/are the major source(s) of perceived stress among the teachers of learners with special needs?

Based on the thematic analysis of the data that emerged from the semi-structured interviews with the participants, two themes emerged as the major sources of the perceived stress among teachers of learners with special needs. These were an unfavourable working environment and motivation.

\subsubsection{Unfavourable Working Environment}

Teachers of learners with special needs who participated in the semi-structured interviews expressed great concern about the deplorable state of the classroom facilities, dilapidated staff rooms, and learners' residences. This concern was raised mainly by the teachers of learners with special needs working in publicly (government) owned special schools. One of the participants, a teacher in a publicly owned special school, had this to say:

Although I have voluntarily signed up to be a teacher of learners with special needs, I feel very bad to teach in this type of classroom where the roof is leaking. When it rains, the classroom is be filled with water, and I have to move the learners to one side of the classroom (TPub 1, Male).

Another participant, a female teacher (TPub 3) from another publicly-owned special school, corroborated the claim of TPub1:

Hmm, the state of facilities in government-owned special schools is nothing to write about... The classroom has been partly demolished by wind storms for more than one year. The floors of the staffrooms are with potholes and not well cemented. The staffrooms have no electricity. Learners' residence is in a worrisome state and above all, teaching resources for these learners are most times sourced for by we, the teachers (TPub 3, Female).

Another teacher had the following to say about the school situation:

It is very frustrating teaching in a special school with this type of deplorable classrooms (TPub 2, Male).

The participants from privately-owned special schools indicated that their facilities were in relatively better shape but that a lot needed to be done. In support of this assertion, TPri 1 said:

The facilities in my school are somewhat okay, but the challenges we are experiencing in this school is that the classrooms are small to accommodate the number of children with special needs currently admitted. There is interference in classrooms. I mean, learners in my classroom are sometimes distracted by the noise coming from another classroom (TPri 1, Female).

\subsubsection{Motivation}

Teachers of learners with special needs were not well motivated. The interviews conducted showed that remuneration was the main source of perceived stress for the teachers. Unfortunately, the teachers interviewed complained bitterly about their salaries compared to the enormous task and activities required by their job. The responses by all the interviewees were similar. TPub 2 stated the following in this regard:

The time I feel most stress being a teacher of learners with special needs is when the salary is paid. The remuneration does not motivate me to do my best for these children. The salary is meagre and, many times, I get angry with myself as a teacher of these children, especially when I think of the stress I had passed through in teaching them (TPub 2, Male).

Similarly, the participants in the privately-owned special schools lamented about how demotivated they were and how stressed they felt about their low salaries. One of the participants from a privately owned special school stated that:

When it comes to stress, special needs education teachers in privately owned schools are overworked and stressed. Unfortunately, they are less paid. Teachers are not well motivated to work at all. When you receive your salary, the expenses outweigh the pay. Then what do you expect? Stressful day(s) or even weeks ahead! (TPri 3, Female). 
Table 4. Independent-sample T-Test of gender, work experience and perceived stress among study participants.

\begin{tabular}{|c|c|c|c|c|c|c|c|}
\hline \multicolumn{2}{|c|}{ Variables } & N & Mean & Std. Dev & Df & t & Sig \\
\hline \multirow{2}{*}{ Gender } & Male & 52 & 18.500 & 6.197 & \multirow{2}{*}{116} & \multirow{2}{*}{-1.462} & \multirow{2}{*}{088} \\
\cline { 2 - 5 } & Female & 66 & 20.060 & 5.383 & & & \\
\hline \multirow{2}{*}{ Work experience } & Early career & 87 & 18.885 & 5.274 & \multirow{2}{*}{116} & \multirow{2}{*}{-1.544} & 0.35 \\
\cline { 2 - 5 } & Late career & 31 & 20.742 & 6.932 & & & \\
\hline
\end{tabular}

\section{DISCUSSION}

A number of studies $[55,56]$ have been conducted on learners with special needs in Nigeria and among Nigerian teachers of learners with special needs [57 - 59]. However, studies on perceived stress among teachers of learners with special needs in Nigeria are scanty, although some studies have indicated that stress is inevitable among teachers in special schools $[7,9,10,14]$. This is because their job is highly emotional and demanding, based on the interconnection between personal characteristics and environment-related factors, as established by the P-E fit theory [17, 48, 49].

Based on the assumptions of the P-E fit theory [48], this study conducted among 118 teachers of learners with special needs found that the student-teacher relationship had a direct and positive correlation with teachers' perceived stress. In other words, a cordial and positive relationship between the teachers and learners with special needs would lower the perceived stress among the teachers. This implied that teachers would not necessarily feel stressed if they experienced positive growth in the behavioural, social, and cognitive capacities of their learners with special needs. This finding corroborated the findings from other studies [11,36, 37].

This study further observed that work experience had inverse relationships with perceived stress among the teachers of learners with special needs. This implied that teachers of learners with special needs who had years of service may inform stress experienced by teaching learners with special needs. This finding provided support for studies $[7,9,11,12$, 14] that assert that teachers in special schools are going through stress. Adeniyi et al. [11] and Kebbi and Al-Hroub [12] argue that the task of teaching learners with special needs is challenging. Kebbi and Al-Hroub [12] note that at all times, teaching learners with special needs require extraordinary efforts from teachers in the curriculum implementation, management of behavioural issues exhibited by the learners in and outside the classroom, application of teaching resources and deployment of pedagogical techniques appropriate to the learners' specific needs.

The findings on research question two, shown in Table $\mathbf{2}$, indicated that all the independent variables collectively predicted perceived stress among the teachers sampled. This finding recognised work motivation and student-teacher relationships factors that jointly influence perceived stress among teachers of learners with special needs. The findings in the current study were in agreement with previous studies [10, $14,27,28,32,33,37,40]$, which had reported links between the independent variables examined in this study and perceived stress. However, few of these studies were conducted among teachers of learners with special needs.

Expressed as standard coefficients, the student-teacher relationship had a positive significant contribution to the perceived stress of teachers of learners with special needs, while work motivation had a negative and insignificant contribution to the perceived stress of teachers of learners with special needs. The implication of this finding was that the student-teacher relationship contributed to a reduction in the perceived stress of the teachers of learners with special needs, while less motivated teachers may experience an increased risk of stress. This finding corroborates Dombrovskis et al. [40] express concern about the effects of a negative work climate, professional stagnation, and undesirable remuneration as a source of stress among teachers. According to Dombrovskis et al. [40], the morale to teach learners with special needs could be very low when teachers were not positively motivated; thus, they may likely experience heightened job stress. Yasmeen et al. [42], in their study among special education teachers, found that the teachers of learners with special needs sampled were intrinsically motivated to execute their duties and have a good relationship with their learners, but the teachers expressed heightened stress levels due to a non-motivating work environment. The result of the present study supported the findings presented by Cornelius-Ukpepi and Opuwari [39].

The finding obtained in this study showed that a significant difference exists in perceived stress among teachers of learners with special needs based on their years of work experiences. In other words, based on the mean value of 18.885 , early career teachers of learners with special needs may experience heightened job stress than colleagues who had spent more years on the job. This finding is not different from Kabito and Wami's [19] as well as Shkëmbi et al. [23], who aver that teachers with lesser years of work experience are prone to work-related stress when compared to other teachers with more than sixteen years of teaching experience. However, our current finding is not in support of some studies [24, 25], which found no relationship between years of teaching experience and perceived stress levels.

The major sources of perceived stress among the teachers of learners with special needs, as observed in this study, were an unfavourable working environment and inadequacy or lack of motivation for teaching learners with special needs. This finding was in support of other studies $[8-12,16,38,60]$, which found that the stress experienced by teachers, especially those of learners with special needs, is high as a result of unfavourable working/teaching environments, coupled with high job demands and low rewards or stimulus packages that are commensurate with the effort they put into teaching learners with special needs. Kebbi and Al-Hroub [12] state that the moderate to high levels of stress experienced by teachers of learners with special needs are attributable to an unfavourable working environment, abysmal conditions of service, poor salaries, and inequitable rewards for the teaching services rendered to learners with special needs.

\section{CONCLUSION}

This study acknowledged the extensive implications of 
environmental factors (work motivation and student-teacher relationship) on perceived stress among teachers of learners with special needs. It can be asserted that despite the positive nature of the student-teacher relationships, teachers of learners with special needs are more stressed when the work environment is not positively stimulated and teachers are not sufficiently positively motivated. The findings of the crosssectional study have implications for special needs teachers' professional practice. In practical terms, governments and other relevant stakeholders in educational systems in Nigeria and across African nations should ensure the increased well-being of teachers of learners with special needs. These teachers should be well remunerated and motivated for them to work efficiently for the positive psychosocial development of learners with special needs. In order to fully achieve the 2030 Sustainable Development Goals, teaching and learning facilities must be conducive to learning. Therefore, effort should be made to ensure that facilities in special schools are adequately equipped, as this will further strengthen a positive work climate.

\section{ETHICS APPROVAL AND CONSENT TO PARTICIPATE}

The study adhered to all ethics of social research conduct the study was given by the University of Zululand Research and Ethics Committee with approval number UZREC 171110-030.

\section{HUMAN AND ANIMAL RIGHTS}

No animals were used in this research. All human research procedures followed were in accordance with the ethical standards of the committee responsible for human experimentation (institutional and national), and with the Helsinki Declaration of 1975, as revised in 2013.

\section{CONSENT FOR PUBLICATION}

Informed consent was obtained from all study participants.

\section{AVAILABILITY OF DATA AND MATERIALS}

Data used for this study is available from the corresponding author [O. T. A.] upon reasonable request.

\section{FUNDING}

None.

\section{CONFLICT OF INTEREST}

The authors declare no conflict of interest, financial or otherwise.

\section{ACKNOWLEDGEMENTS}

Declared none.

\section{REFERENCES}

[1] Adigun OT. Basic education in Nigeria: Any concern for special needs education? J Adv Rehab 2018; 17(1): 27-37.

[2] Raffaele Mendez LM, Kim ES, Ferron J, Woods B. Altering school progression through delayed entry or kindergarten retention: Propensity score analysis of long-term outcomes. J Educ Res 2015; 108(3): 186-203.

[http://dx.doi.org/10.1080/00220671.2013.867474]
[3] UNICEF. Impact Evaluaon of UNICEF Nigeria Girls' Educaon Project Phase 3 (GEP3) Cash Transfer Programme (CTP) in Niger and Sokoto States. 2017. Available from: https://www.unicef.org/nigeria/sites/unicef.org.nigeria/files/2018-09/N igeria-impact-evaluation-UNICEF-Nigeria-girls-education-projectphase-3.pdf

[4] Abang TB. Special education in Nigeria. Int J Disabil Dev Educ 1992; 39(1): 13-8.

[http://dx.doi.org/10.1080/0156655920390103]

[5] Adetoro RA. Inclusive education in Nigeria - A Myth or reality? Creat Educ 2014; 5(20): 1777.

[http://dx.doi.org/10.4236/ce.2014.520198]

[6] Osisanya A, Oyewumi AM, Adigun OT. Perception of parents of children with communication difficulties about inclusive education in Ibadan metropolis. Af J Educ Res 2015; 19(1): 21-32.

[7] Cancio EJ, Larsen R, Mathur SR, Estes MB, Johns B, Chang M. Special education teacher stress: Coping strategies. Educ Treat Child 2018; 41(4): 457-81.

[http://dx.doi.org/10.1353/etc.2018.0025]

[8] Kokkinos CM, Davazoglou AM. Special education teachers under stress: Evidence from a Greek national study. Educ Psychol 2009; 29(4): 407-24.

[http://dx.doi.org/10.1080/01443410902971492]

[9] Kuvaeva I. Teachers of special schools: Stressors and manifestations of occupational stress. KnE Life Sciences 2018; 515-21.

[10] Adeniyi SO, Fakolade OA, Tella A. Perceived causes of job stress among special educators in selected special and integrated schools in nigeria. New Horizons Educ 2010; 58(2): 73-82. Available from: https://files.eric.ed.gov/fulltext/EJ966651.pdf

[11] Ghani MZ, Ahmad AC, Ibrahim S. Stress among special education teachers in Malaysia. Procedia Soc Behav Sci 2014; 114: 4-13.

[http://dx.doi.org/10.1016/j.sbspro.2013.12.648]

[12] Kebbi M, Al-Hroub A. Stress and coping strategies used by special education and general classroom teachers. Int J Spec Educ 2018; 33(1): 34-61.

[13] Lazarus RS. Stress and emotion: A new synthesis. Springer Publishing Company 2006.

[14] Eskay M, Nwefuru BC. Cross-sectional study of perceived stress among special education teachers. Glob J Health Sci 2019; 11(14): 123-7.

[http://dx.doi.org/10.5539/gjhs.v11n14p123]

[15] Federal Ministry of Education. Teachers Registration Council of Nigeria CAP T3 of 2004 Abuja 2004. Available from: https://rcn.gov.ng/ACT/TRCN\%20Act.pdf

[16] Mohammed A, El-Jajah GW. Payment of teachers' salary and promotion as correlate of teachers' job performance in senior secondary schools in Adamawa State. Nigeria. Int J Philos SocialPsychol Sci 2019; 5(4): 39-46.

[17] Okeke CIO, Dlamini CC. An empirical study of stressors that impinge on teachers in secondary schools in Swaziland. South Afr J Educ 2013; 33(1): 1-12.

[http://dx.doi.org/10.15700/saje.v33n1a607]

[18] Aftab M, Khatoon T. Demographic differences and occupational stress of secondary school teachers. Eur Sci J 2012; 8(5): 159-75. Available from:

http://citeseerx.ist.psu.edu/viewdoc/download?doi=10.1.1.909.85\&rep $=$ rep $1 \&$ type $=$ pdf

[19] Kabito GG, Wami SD. Perceived work-related stress and its associated factors among public secondary school teachers in Gondar city: A cross-sectional study from Ethiopia. BMC Res Notes 2020; 13(1): 36. [http://dx.doi.org/10.1186/s13104-020-4901-0] [PMID: 31952547]

[20] Darmody M, Smyth E. Job satisfaction and occupational stress among primary school teachers and school principals in Ireland. Maynooth Business Campus: Ireland Teaching Council 2011. Available from: https://www.esri.ie/publications/job-satisfaction-and-occupational-stre ss-among-primary-school-teachers-and-school-principals-in-ireland

[21] Berger JL, Girardet C, Vaudroz C, Crahay M. Teaching experience, teachers' beliefs, and self-reported classroom management practices: A coherent network. SAGE Open 2018; 8(1): 1-12.

[http://dx.doi.org/10.1177/2158244017754119]

[22] Morris-Rothschild BK, Brassard MR. Teachers' conflict management styles: The role of attachment styles and classroom management efficacy. J Sch Psychol 2006; 44: 105-21.

[http://dx.doi.org/10.1016/j.jsp.2006.01.004]

[23] Shkëmbi F, Melonashi E, Fanaj N. Workplace stress among teachers in Kosovo. SAGE Open 2015; 5(4): 1-8. [http://dx.doi.org/10.1177/2158244015614610] 
[24] Johannsen SE. An analysis of the occupational stress factors identified by certified teachers 2011. Available from: http:// digitalcommons.georgiasouthern.edu/cgi/viewcontent. cgi? article $=1377 \&$ context $=$ etd

[25] Platsidou M, Agaliotis I. Burnout, job satisfaction and instructional assignment-related sources of stress in Greek Special Education Teachers. Int J Disabil Dev Educ 2008; 55(1): 61-76. [http://dx.doi.org/10.1080/10349120701654613]

[26] Eisenhower AS, Baker BL, Blacher J. Early student-teacher relationships of children with and without intellectual disability: Contributions of behavioral, social, and self-regulatory competence. J Sch Psychol 2007; 45(4): 363-83.

[http://dx.doi.org/10.1016/j.jsp.2006.10.002] [PMID: 21490876]

[27] Koenen AK, Vervoort E, Verschueren K, Spilt JL. Teacher-student relationships in special education: The value of the teacher relationship interview. J Psychoed Assess 2019; 37(7): 874-86.

[http://dx.doi.org/10.1177/0734282918803033]

[28] Lopez C, Corcoran T. Relationships with special needs students: Exploring primary teachers' descriptions. Int J Incl Educ 2014; 18(12): 1304-20.

[http://dx.doi.org/10.1080/13603116.2014.897385]

[29] Prino LE, Pasta T, Gastaldi FGM, Longobardi C. A study on the relationship between teachers and students with special needs. Int $\mathrm{J}$ Devel Edu Psychol 2014; 3(1): 119-28.

[http://dx.doi.org/10.17060/ijodaep.2014.n1.v3.488]

[30] Hughes JN, Kwok OM. Classroom engagement mediates the effect of teacher-student support on elementary students' peer acceptance: A prospective analysis. J Sch Psychol 2006; 43(6): 465-80.

[http://dx.doi.org/10.1016/j.jsp.2005.10.001] [PMID: 20431706]

[31] Koenen AK, Vervoort E, Kelchtermans G, Verschueren K, Spilt JL. Teachers' daily negative emotions in interactions with individual students in special education. J Emot Behav Disord 2019; 27(1): $37-51$.

[http://dx.doi.org/10.1177/1063426617739579]

[32] Pianta RC, Steinberg M. Teacher-child relationships and the process of adjusting to school.Beyond the parent: The role of other adults in children's lives New directions for child development. San Francisco, CA: Jossey-Bass 1992; Vol. 57: pp. 81-107. [http://dx.doi.org/10.1002/cd.23219925706]

[33] Pianta RC, Stuhlman MW. Teacher-child relationships and children's success in the first years of school. School Psych Rev 2004; 33(3): 444-58.https://psycnet.apa.org/record/2004-19926-011 [http://dx.doi.org/10.1080/02796015.2004.12086261]

[34] Brunsting NC, Sreckovic MA, Lane KL. Special education teacher burnout: A synthesis of research from 1979 to 2013. Educ Treat Child 2014; 37(4): 681-711.

[http://dx.doi.org/10.1353/etc.2014.0032]

[35] Kiel E, Heimlich U, Markowetz R, Braun A, Weiß S. How to cope with stress in special needs education? Stress-inducing dysfunctional cognitions of teacher students: The perspective of professionalisation. Eur J Spec Needs Educ 2016; 31(2): 202-19.

[http://dx.doi.org/10.1080/08856257.2015.1125693]

[36] Scruggs T, Mastropieri MA. Teacher perceptions of mainstreaming/inclusion 1958-1995: A research synthesis. Except Child 1996; 63(1): 59-74.

[http://dx.doi.org/10.1177/001440299606300106]

[37] Shevlin M, Winter E, Flynn P. Developing inclusive practice: Teacher perceptions of opportunities and constraints in the Republic of Ireland. Int $\mathrm{J}$ Incl Educ 2012; 17(10): 1119-33. Available from: http://hdl.handle.net/2262/68190

[http://dx.doi.org/10.1080/13603116.2012.742143]

[38] Adepoju A, Fabiyi A. Universal Basic Education in Nigeria: Challenges and Prospects 2007. Available from: http://uaps2007.princeton.edu/download.aspx?submissionId $=70830$

[39] Cornelius-Ukpepi BU, Opuwari OS. Determinants of effective implementation of inclusive education at the basic education level in Nigeria. British. J Educ 2019; 7(8): 34-44. Available from: https://www.eajournals.org/wp-content/uploads/Determinants-of-Effec tive-Implementation-of-Inclusive-Education-at-the-Basic-EducationLevel-in-Nigeria.pdf

[40] Dombrovskis V, Guseva S, Murasovs V. Motivation to work and the syndrome of professional burn-out among Teachers in Latvia. Procedia Soc Behav Sci 2011; 29: 98-106. [http://dx.doi.org/10.1016/j.sbspro.2011.11.212]

[41] Göktürk S, Tülübaş T, Bozoğlu O. A motivational perspective on teacher retention in special education: A critical case from Turkey. Educ Res Policy Pract 2020; 1-16.

[http://dx.doi.org/10.1007/s10671-020-09267-5]

[42] Yasmeen Z, Mushtaq I, Murad M. Intrinsic and extrinsic motivation of teachers in special education secondary school: A qualitative study. $\mathrm{J}$ Educ Res 2019; 22(2): 15-30.

[43] Eyal O, Roth G. Principals' leadership and teachers' motivation. J Educ Adm 2011; 49(3): 256-75. [http://dx.doi.org/10.1108/09578231111129055]

[44] Lazarus K, Mohammed O, Adigun O. Family and teachers factors as determinant of career decisions among adolescents with hearing impairment in Ogun State, Nigeria. J Educ Pract 2013; 4(8): 161-8.www.iiste.org

[45] Amalu MN, Uche RD. Stress arising from motivation and professional effectiveness of secondary school teachers in Cross River State. Brock J Educ 2014; 2(4): 73-84. Available from: http://www.eajournals.org/wp-content/uploads/Stress-Arising-from-M otivation-and-Professional-Effectiveness-of-Secondary-School-

Teachers-in-Cross-River-State1.pdf

[46] Skaalvik EM, Skaalvik S. Still motivated to teach? A study of school context variables, stress and job satisfaction among teachers in senior high school. Soc Psychol Educ 2017; 20(1): 15-37. [http://dx.doi.org/10.1007/s11218-016-9363-9]

[47] Lindqvist H, Thornberg R, Lindqvist G. Experiences of a dual system: Motivation for teachers to study special education. Eur J Spec Needs Educ 2020; 1-15.

[http://dx.doi.org/10.1080/08856257.2020.1792714]

[48] French JRP. Adjustment as person-environment fit. In: G. V. Coelho, D. A. Hamburg, J. E. Adams, Eds. Coping and adaptation. New York: Basic Books 1974.

[49] Yu KYT. A motivational model of person-environment fit: Psychological motives as drivers of change.Organizational Fit: Key Issues and New Directions. Chichester, UK: Wiley-Blackwell 2013; pp. 19-49.

[50] Cohen L, Manion L, Morrsion K. Research methods in education. $7^{\text {th }}$ ed. London, England: Routledge 2011.

[51] Pianta RC. Student-Teacher Relationship Scale: Professional Manual. Odessa, FL: Psychological Assessment Resources, Inc. 2001.

[52] Tremblay M A, Blanchard C M, Taylor S, Pelletier L G, Villeneuve M. Work Extrinsic and Intrinsic Motivation Scale: Its value for organizational psychology research. Canadian J Behavi Sci 2009; 414 [http://dx.doi.org/10.1037/a0015167]

[53] Cohen S, Kamarck T, Mermelstein R. Perceived stress scale. Measuring stress: A guide for health and social scientists 1994; 10: $1-2$.

[http://dx.doi.org/10.13072/midss.461]

[54] Bryman A. Social research methods. Oxford university press 2016.

[55] Adigun OT. Depression and individuals with hearing loss: A systematic review. J Psychol Psychother 2017; 7(5): 323.

[http://dx.doi.org/10.4172/2161-0487.1000323]

[56] Olaoluwa SA, Ayantoye CA. Impact of brain-based instructional strategy on academic performance of deaf students in mathematics in Oyo School of Handicapped, Nigeria. World J Educa Res 2016; 3(2): 447-559.

[http://dx.doi.org/10.22158/wjer.v3n2p447]

[57] Adigun OT. Computer-assisted instruction, project based learning and achievement of Deaf learners in Biology. J E-Learning Knowl Soc 2020; 16(1): 23-32.

[http://dx.doi.org/10.20368/1971-8829/1135190]

[58] Ajuwon PM. Inclusive education for students with disabilities in Nigeria: Benefits challenges and policy implications. Int J Spec Educ 2008; 23(3): 1-6. Available from: https://files.eric.ed.gov/fulltext/EJ833673.pdf

[59] Oyewumi AM, Akangbe T, Adigun OT. Personality factors as correlates of perceived quality of life among adolescents with hearing impairment in selected secondary schools in Lagos State, Nigeria. J Educ Pract 2013; 4(9): 162-8. Available from: www.iiste.org

[60] Amstad M, Müller CM. Students' problem behaviors as sources of teacher stress in special needs schools for individuals with intellectual disabilities. Front Educ 2020; 4: 159. [http://dx.doi.org/10.3389/feduc.2019.00159] 